\title{
Ultra-sonographic image of ovarian mass and increased CA 19-9 levels as a pre-operative diagnostic predictor of mature cystic teratoma of ovary
}

\section{Malla $\mathrm{S}^{1}$, Fan $\mathrm{J}^{2}$, Vaidya $\mathrm{T}^{3}$}

'Sameer Malla, Lecturer, Department of Gynecology \& Obstetrics, Shree Birendra Hospital,Chhauni, Kathmandu, Nepal; 2 Jiangtao Fan, Associate Professor, Department of Gynecology \& Obstetrics, The First Affiliated Hospital, Guangxi Medical University, Guangxi, China; ${ }^{3}$ Tripti Vaidya, Department Of Radiology, Kanti Children's Hospital

\begin{abstract}
Introduction: Mature cystic teratoma of ovary, categorized as germ cell tumor is commonly seen in females of reproductive age group. The main aim of this study is to evaluate the serum level of CA 19-9 in those patients.

Methods: A prospective study on 65 patients at First Affiliated Hospital, Guangxi Medical University, China within the period of one year. Patients underwent pelvic examination, ultra-sonograph and evaluation of serum level of CA 19-9, CA 125, CEA, AFP and SCCA prior to surgery. Following the surgery,samples were subjected for histo-pathological analysis where confirmatory diagnosis of Mature Cystic teratoma of ovary was established. Serum CA 19-9 was then re-analyzed following surgical removal of the tumor.

Results: Mean age of patients with mature Cystic teratoma was 32.5 \pm 12.1 years (range 15-71). Mean tumor diameter was $5.8 \pm 2.4 \mathrm{~cm}$ (range 2.3-12.2). Serum level of CA19-9 was the only tumor marker with a mean serum level (49.9 $\pm 73.41 \mathrm{U} /$ $\mathrm{ml}$ ) above the cut-off value and its elevated rate was $30.76 \%$. Rate of bilateral tumors was $16.9 \%$. The tumor size was significantly higher in patients with elevated CA 19-9 than those with normal CA 19-9. There was significant difference in the serum level of CA 19-9 before and after the surgery $(p<0.002)$ in patients with elevated level of CA 19-9 pre-operatively. Conclusion: Among all subjects who underwent pelvic ultrasonography imaging and analysis of tumor markers (CA 19-9, CA 125, CEA, AFP and SCCA) prior to surgery, serum level of CA 19-9 has the highest positivity rate in mature cystic teratomas of ovary and its level decreases following surgical removal.
\end{abstract}

Key words: CA 19-9, mature cystic teratoma ovary, ultra-sonography

\section{INTRODUCTION}

$\mathrm{M}$ ature Cystic Teratoma (MCT) belongs to nonepithelial germ cell tumor of the ovary, often encountered during reproductive age. It accounts for 27-44 \% of all ovarian tumors ${ }^{1}$ with involvement of bilateral ovaries in $12 \%$ of the cases ${ }^{2}$. Majority of the patients present with pain in and around abdomen, mass per abdomen, torsion causing severe pain or at worse rupture leading to peritonitis. However, some cases may be incidentally diagnosed during routine pelvic examination and imaging. Overall incidence of malignancy is rare and occurs in $1 \%$ of the cases, most common being squamous cell carcinoma ${ }^{3}$.

Address for correspondence

\section{Dr. Sameer Malla}

Lecturer, Department of Gynecology \& Obstetrics,

Shree Birendra Hospital, Chhauni, Kathmandu, Nepal.

E-mail: mallasameer@hotmail.com
In order to prevent complications, it is recommended to remove ovarian MCTs whenever they are found. One should emphasize on fertility conserving surgery such as ovarian cystectomy since most patients belong to younger age group.

Various serum tumor markers have been used in the diagnosis, management, monitoring disease response to treatment, detecting disease recurrence and estimating prognosis of pelvic masses. Beside accurate sonographic diagnosis of ovarian MCTs in most cases, role of serum tumor marker (CA 19-9) has been shown to provide additional information about the tumor, aid in making a differential diagnosis and help surgeons decide the type of surgery to be performed ${ }^{4}$.

CA 19-9 is a tumor associated cancer antigen with a glycolipid structure $^{5}$. It is present in relatively high concentrations in prostatic, gastric, amniotic 
fluids, excretions of pancreas and duodenum of healthy individuals. CA 19-9 was initially described in gastrointestinal adenocarcinornas. However, its presence may indicate any tissue malignancy ${ }^{5}$ which in a few studies have reported the usefulness in patients with MCT of the ovary ${ }^{6-8}$. Elevated rate of CA19-9 varies between $31.9 \%$ to $59 \%$ and extreme levels up to $1430 \mathrm{U} /$ $\mathrm{ml}$ have been reported ${ }^{6,9,10}$. Presence of CA19-9 in serum is probably explained by the leakage of carcinogenic antigen from cystic cavity to serum resulting from inflammation and thinning out of the cyst wall following the enlargement of the cyst.

Elevation of CA 19-9 in patients with MCT and decrease in its level after surgical intervention have been reported at few instances in literature ${ }^{4,11,12}$, we analyzed the relationship between serum levels of CA 19-9 with other variables viz; age, size of the cyst, menopausal status of the women and presence of bilateral cyst in patients with MCT. Furthermore, the diagnostic and prognostic value of serum levels of CA19-9 is investigated.

\section{METHODS}

Sixty five cases of mature cystic teratoma of ovary treated surgically with histopathology evidence at The First Affiliated Hospital, Guangxi Medical University, Department of Gynecology for a period of one year were taken as study subjects.

All the patients underwent pelvic examinations by the consultant gynecologist along with pelvic ultrasonography prior to surgery to determine the characteristics of the ovarian tumor. The variables analyzed included age of the patient, average diameter of the tumor, site of tumor (right or left ovary), bilaterality, menopausal status and serum levels of five tumor markers in case of MCT. Serum tumor markers analyzed were Cancer antigen 125(CA 125), Carbohydrate antigen 19-9 (CA 19-9), Alpha-fetoprotein (AFP), Carcino-embryogenic antigen (CEA) and Squamous cell carcinoma antigen (SCCA). Blood samples were collected from all patients preoperatively.

Patients were divided into two different groups based on the pre-operative serum levels of CA 19-9, elevated CA 19-9 group (Group A) and normal CA19-9 group (Group B). In patients with elevated levels of CA19-9 before the surgery, blood samples were collected again after 3-5 days of surgery after histopathology confirmation of MCT. However serum levels of tumor markers in patients with pre-operative normal CA 19-9 was not done after the surgery. Pre-operative, post-operative levels of serum CA19-9 and its correlation with the diameter of tumor, age, bilaterality and menopausal status were compared. The cut-off values for CA 19-9, CA 125, AFP, CEA, and SCCA were accepted as $37 \mathrm{IU} / \mathrm{mL}, 35 \mathrm{U} / \mathrm{mL}, 11 \mathrm{ng} / \mathrm{mL}, 5$ $\mathrm{ng} / \mathrm{mL}$ and $1.5 \mathrm{ng} / \mathrm{mL}$ respectively. Cases which couldn't be confirmed as MCT of ovary by histopathology report were not included for analysis. Data analysis was done using SPSS version 17. Statistical evaluation of the data was performed by the student's $t$-test, chi-square test, Mann Whitney U test and Pearson's test.

\section{RESULTS}

A total of 65 cases were diagnosed as mature cystic teratoma during the study period with the mean age being $32.5 \pm 12.1$ years (median 28; range 15-71).Overall, eight patients $(12.3 \%)$ were in the post-menopausal period. Size of the tumor ranged from 2.3 to $12 \mathrm{~cm}$ in diameter with a median, mean and standard deviation calculated to be $5.6 \mathrm{~cm}$ and $5.8 \pm 2.33 \mathrm{~cm}$ respectively. In group $A$ there was a moderate positive correlation of CA19-9 levels to the diameter of the tumor $(r=0.48$, $\mathrm{p}<0.05)$ but there was no such correlation in group $B$ $(r=0.18, p=0.27)$.

Bilateral tumors were observed in $20 \%$ of the cases and unilateral tumors were more common on the right side (29 patients, 55.7\%) than the left (23 patients, $44.2 \%$ ). Only one patient presented with the complication of ruptured ovarian cyst with CA 19-9 level well below the normal value. No cases of malignant transformations were reported in any subjects.

As shown in Table 1, there was no statistically significant difference in terms of patient age and menopause between groups A and B. There were 4 patients (20\%) in group $A$ with bilateral tumors in comparison with nine patients $(20 \%)$ in group $B(p=1.00)$. The mean tumor diameter of group $A$ was significantly greater than group $B(6.92 \pm 2$ vs. $5.18 \pm 2.3 \mathrm{~cm}, \mathrm{p}=0.003)$.

Among all tumor markers CA19-9 was the only tumor marker with the mean serum level above the cut-off value and with highest elevation rate. None of the tumor markers including CA19-9 showed an elevated rate of $\geq$ $50 \%$ (Table 2).

Table 3 illustrates that beside serum levels of CA19-9, the elevation rate of CA 125 is highest compared to other tumor markers in both groups and the rate of elevated CA 125 is statistically significant in group A. Serum level of CEA was within normal limit in all cases. Out of 65 subjects, serum levels of CA 19-9 and CA 125 was within the cut off value in 45 and 37 patients respectively. In six patients (9.2\%) CA125 was raised with normal CA 19-9 
levels. In $16.9 \%$ of the patients, CA19-9 and CA 125 levels were raised above the normal values.

As shown in table 4, Post-operative assessment of CA 19-9 levels in 20 patients of group A, who had elevated levels preoperatively revealed that mean CA 19-9 level was decreased from $131.44 \pm 88.5$ to $66.9 \pm 32.64 \mathrm{U} / \mathrm{ml}$, and the difference was statistically significant $(p=0.001)$.

\section{DISCUSSION}

In our study, median age of our patients with MCT were 32.5 years which was consistent with other studies ${ }^{4,13}$. Mean tumor diameter of MCTs in the literatures ${ }^{9,14}$ range between 6.4 and $8.8 \mathrm{~cm}$, which was almost consistent with our study $(5.8 \mathrm{~cm})$. MCTs of theovary in some studies were reliably identified with ultrasonography ${ }^{15,16}$.

Our study demonstrated that elevated levels of CA19-
9 in serum is directly proportional to the size of MCT $(r=0.48)$ but the levels were not correlated with the bilaterality of the tumor. Both these results were found to be consistent with study done by Emin et al ${ }^{4}$ correlating size of tumor with levels of CA19-9 and Dede et $a l^{11}$ in bilateral tumors.

Only $12.3 \%$ of the women were post menopausal and no clear associations were seen between serum level of CA19-9 and menopausal status of the patients.

A benign ovarian tumor, MCTs should be removed surgically as complications occur in $20 \%$ of the cases ${ }^{2}$. We encountered only one case which presented as ruptured cyst. Low rate of complications in this study is probably due to the fact that most of the cases of MCTs were diagnosed during routine medical examinations or radiological evaluations done for other purposes.

Table 1: Clinical characteristics of patients with and without an elevated serum CA19-9 level

\begin{tabular}{|c|c|c|c|c|c|}
\hline \multirow{3}{*}{$\begin{array}{c}\text { Clinical } \\
\text { characteristics } \\
\text { Age(Years) }\end{array}$} & \multicolumn{2}{|c|}{ Group $A(n=20)$} & \multirow{2}{*}{\multicolumn{2}{|c|}{$\begin{array}{l}\text { Group B(n=45) } \\
\text { Mean } \pm \text { SDRange }\end{array}$}} & \multirow{3}{*}{$\begin{array}{c}\mathbf{p} \\
0.831\end{array}$} \\
\hline & \multirow{2}{*}{$\begin{array}{l}\text { Mean } \pm \text { SD } \\
31.3 \pm 10.5\end{array}$} & \multirow{2}{*}{$\begin{array}{l}\text { Range } \\
20-65\end{array}$} & & & \\
\hline & & & $33.02 \pm 12.82$ & $15-71$ & \\
\hline $\begin{array}{l}\text { Diameter of tumor } \\
\qquad(\mathrm{cm})\end{array}$ & $6.92 \pm 2.0$ & $2.23-11.25$ & $5.2 \pm 2.3$ & $2.63-12.2$ & 0.003 \\
\hline Bilaterality & $4(20 \%)$ & - & $9(20 \%)$ & - & 1.00 \\
\hline Menopause & $2(10 \%)$ & - & $6(13.34 \%)$ & - & 1.00 \\
\hline
\end{tabular}

Table 2: The elevated rates of different tumor markers in patients with MCT.

\begin{tabular}{cccccc}
\hline Tumor marker & $\mathbf{n}$ & Cutoff value & $\begin{array}{c}\text { Serum level } \\
\text { (mean } \pm \text { SD) }\end{array}$ & Range & $\begin{array}{c}\text { Elevated rate(n/ } \\
\text { total) }\end{array}$ \\
\hline CA 19-9(U/ml) & 65 & 37 & $49.94 \pm 73.4$ & $0.60-370.9$ & $30.76 \%(20 / 65)$ \\
\hline CA 125 $(\mathrm{U} / \mathrm{ml})$ & 63 & 35 & $30.5 \pm 34.25$ & $4-140$ & $26.9 \%(17 / 63)$ \\
\hline AFP $(\mathrm{ng} / \mathrm{ml})$ & 65 & 11 & $13.42 \pm 63.3$ & $0.97-480.7$ & $4.61 \%(3 / 65)$ \\
\hline SCCA $(\mathrm{ng} / \mathrm{ml})$ & 65 & 1.5 & $0.90 \pm 0.46$ & $0.30-2.70$ & $7.69 \%(5 / 65)$ \\
\hline CEA $(\mathrm{ng} / \mathrm{ml})$ & 65 & 5.0 & $1.56 \pm 1.04$ & $0.34-4.53$ & $0.0 \%(0 / 65)$ \\
\hline
\end{tabular}

Table 3: Differences in elevation rates of pre- operative levels of tumor markers in Group A and Group B

\begin{tabular}{|c|c|c|c|c|c|c|c|}
\hline \multirow{3}{*}{$\begin{array}{c}\begin{array}{c}\text { Tumor } \\
\text { Markers }\end{array} \\
\text { CA 19-9 }(\mathrm{U} / \mathrm{ml})\end{array}$} & \multicolumn{3}{|c|}{ GROUP A $(n=20)$} & \multirow{2}{*}{\multicolumn{3}{|c|}{$\begin{array}{c}\text { GROUP B(n=45) } \\
\text { Mean } \pm \text { SD Range Elevated(\%) }\end{array}$}} & \multirow{3}{*}{$\begin{array}{c}\mathbf{p} \\
0.000\end{array}$} \\
\hline & \multirow{2}{*}{$\begin{array}{r}\text { Mean } \pm \text { SD } \\
131.44 \pm 88.49\end{array}$} & \multirow{2}{*}{$\begin{array}{c}\text { Range } \\
41.47-370.9\end{array}$} & Elevated (\%) & & & & \\
\hline & & & $100 \%(20)$ & $13.73 \pm 9.66$ & $0.60-33.64$ & $0.0 \%(0)$ & \\
\hline CA $125(\mathrm{U} / \mathrm{ml})$ & $55.34 \pm 46.90$ & $6.1-140.7$ & $55 \%(11)$ & $18.98 \pm 17.52$ & 4-103.6 & $13.9 \%(6 / 43)$ & 0.000 \\
\hline CEA (ng/ml) & $1.83 \pm 1.16$ & $0.34-4.53$ & $0.0 \%(0)$ & $1.45 \pm 0.98$ & $0.5-4.47$ & $0.0 \%(0)$ & - \\
\hline SCCA (ng/ml) & $1.12 \pm 0.57$ & $0.30-2.70$ & $15 \%(3)$ & $0.81 \pm 0.38$ & $0.3-2.24$ & $6.6 \%(3)$ & 0.361 \\
\hline $\operatorname{AFP}(\mathrm{ng} / \mathrm{ml})$ & $37.43 \pm 112.28$ & $0.97-480.7$ & $15 \%(3)$ & $2.76 \pm 1.48$ & $1.28-8.13$ & $0.0 \%(0)$ & 0.315 \\
\hline
\end{tabular}

Table 4: Serum level of CA19-9 before and after the surgery

\begin{tabular}{cccc} 
& Pre-Operative $(\mathbf{n}=\mathbf{2 0})$ & Post-operative $(\mathbf{n}=\mathbf{2 0})$ & $\mathbf{p}$ \\
CA19-9 & $131.44 \pm 88.8$ & $66.9 \pm 32.6$ & 0.001 \\
\hline
\end{tabular}


None of the cases in our study showed malignant transformations. Literature has reported that $1-2 \%$ of the cases of MCT undergo malignant transformation, most frequently in post menopausal women ${ }^{14,17}$. According to gynecologic oncology reports, malignant transformation is very rare in patients younger than 45 years, tumor size less than $9.9 \mathrm{~cm}$, and the serum SCCA level less than 2 $\mathrm{ng} / \mathrm{ml}$ in which case the epithelial components of MCT commonly transform into squamous carcinoma ${ }^{14,16}$.

In this study, the mean value of CA 19-9 in patients with MCT in group A decreased significantly from $131.44 \pm 88.5$ $\mathrm{IU} / \mathrm{ml}$ pre-operatively to $66.9 \pm 32.6 \mathrm{IU} / \mathrm{ml}$ post surgery. This is consistent withb ITo et al. who evaluated 250 patients of MCT of the ovary and they reported that the initial high levels of CA 19-9 were reduced to normal within 2 weeks after tumor resection ${ }^{12}$.

In our study, the elevated rate of CA125 in patients with MCT was $26.9 \%$.In patients of group $A$, serum level of $C A$ 125 was also elevated in $55 \%$ of the cases. CA-125 is the most widely used tumor marker in ovarian malignancy and is elevated in $1 \%$ of the healthy populations, in patients with endometriosis, pelvic inflammatory disease, early pregnancy, liver cirrhosis, pancreatitis and intra abdominal non ovarian malignancy ${ }^{18}$. Its value cannot be used alone for the diagnosis of MCT and furthermore simultaneous increase in serum level of CA 19-9 and CA 125 is not always associated with ovarian malignancy.

\section{CONCLUSION}

Compared to other four tumor markers (CA 125, SCCA, AFP and (EA), the increase in serum level of CA 19-9 along with sonographical evidence adds corroborative value in the diagnosis of mature cystic teratoma of ovary which helps in early detection, prediction and prevention of surgical intervention like biopsy, FNAC etc, for mere diagnostic purpose; particularly in tumor of bigger sizes irrespective of bilaterality and menopausal status of young female in her reproductive age.

9. Kikkawa F, Nawa A, Tamakoshi K et al. Diagnosis of squamous cell carcinoma arising from mature cystic teratoma of the ovary. Cancer. 1998;82:2249-55.

10. Kyung MS, Choi JS,Hong SH, Kim HS. Elevated CA 19-9 levels in mature cystic teratoma of the ovary. Int J Biol Markers. 2009;24:52-56

11. Dede M, Gungor S,Yenen M.C, Alanbay I, Duru N.K, Hasimi A. CA19-9 may have clinical significance in mature cystic teratomas of the ovary. Int J gynecol Cancer. 2006;16:189-93.

12. ITo K. CA19-9 in mature cystic teratoma. The Tohoku journal of experimental medicine. 1994;172(2):1338.

13. Sah SP, Uprety D, Rani S. Germ cell tumors of the ovary: a clinicopathologic study of 121 cases from Nepal. Journal of Obstetrics and Gynaecology Research. 2004 Aug 1;30(4):303-8.

14. Comerci J Jr, Licciardi F, Bergh PA, Gregori C, Breen JL. Mature cystic teratoma: a clinicopathologic evaluation of 517 cases and review of the literature. Obstet Gynecol. 1994;84:22-8.

15. Patel M.D, Feldstein V.A, Lipson S.D, Chen D.C, Filey R.A. Cystic terstomas of the ovary: diagnostic value of sonography. AJR Am J Roentgenol. 1998; 71(4):1061-1065.

16. Ferrazzi E, Zanetta G, Dordoni D, Berlanda N, Mezzopane R, Lissoni G. Transvaginalultrasonographic characterization of ovarian masses: comparision of five scoring systems in a multicenter study. Ultrasound Obstet Gynecol. 1997;10:192-7. 
17. Peterson W.F, Prevost E.C, Edmunds F.T, Hundly J.M Jr, Morris F.K. Benign cystic teratomas of ovary-a clinico-statistical study of 1007 cases with a review of the literature. Am. J. Obstet. Gynecol. 1955;70:368-82.
18. Jacobs I, Oram D, Fairbanks J, Turner J, Frost C, Grudzinskas JG. A risk of malignancy index incorporating CA 125, ultrasound and menopausal status for the accurate preoperative diagnosis of ovarian cancer. BJOG: An International Journal of Obstetrics \& Gynaecology. 1990 Oct 1;97(10):922-9. 